\title{
Neurosurgery for Psychopaths? An Ethical Analysis
}

Dietmar Hübner and Lucie White

\section{Accepted Manuscript Version. Published (2016) in AJOB Neuroscience, 7(3): 140-9. http://dx.doi.org/10.1080/21507740.2016.1218376}

\begin{abstract}
Recent developments in neuroscience have inspired proposals to perform deep brain stimulation on psychopathic detainees. We contend that these proposals cannot meet important ethical re-quirements that hold for both medical research and therapy. After providing a rough overview of key aspects of psychopathy and the prospects of tackling this condition via deep brain stimula-tion, we proceed to an ethical assessment of such measures, referring closely to the distinctive features pf psychopathic personality, particularly the absence of subjective suffering and a lack of moral motivation. Scrutiny of these factors reveals that two essential bioethical criteria, individual medical benefit and voluntary informed consent, cannot be met in performing neurosurgical experiments or treatments on psychopathic inmates.
\end{abstract}

\section{Introduction ${ }^{1}$}

Recent advances in modern neuroscience have encouraged considerations concerning the possible application of neuroscientific technologies in the forensic sector. These include the idea of neurosurgical interventions in delinquents classified as "psychopathic". To be sure, these applications are still in an early phase of design and discussion. Consequently, it is neither obvious that they will ever be brought into widespread operation (for both technical and political reasons), nor is it clear exactly what form these interventions might eventually take. Nevertheless, the prospect of such techniques emerging is plausible enough to warrant discussion and evaluation (particularly as there are concrete suggestions and early attempts to develop and use them), and their basic normative implications can be carved out notwithstanding their still visionary nature.

\footnotetext{
${ }^{1}$ The authors are indebted to Stephan Schleim for bringing their attention to the topic. They also thank Stephan Schleim and Felix Schirmann for helpful discussions of a first draft and for valuable hints to important literature, as well as the two anonymous reviewers from $A J O B$ Neuroscience for providing useful comments on an earlier ver-sion of this paper.
} 
Even in these early stages, a specific proposal in this area has been the focus of advocacy (Hoeprich 2009; Merkel et al. 2007) and debate (De Ridder et al. 2009; Gkotski and Benaroyo 2012). It suggests the use of deep brain stimulation (DBS), i.e. the insertion of pacemakers, stimulators, probes, etc., into an imprisoned psychopath's brain, with the aim of influencing or even controlling her criminal behavior. In what follows, we will focus on this particular scenario. That is, first, the target interventions of our analysis are deep brain stimulation techniquesnot other neuroscientific approaches, particularly when they are non-invasive, such as neurofeedback. It is possible, however, that some of the ethical implications of this paper could be extended to a wider array of neuroscientific procedures, including psychochemical or psychopharmacological interventions, as long as they are comparably burdensome and risky. Second, the targetpopulation of our analysis are imprisoned psychopaths - neither psychopaths that have not committed a crime but live their private and professional lives peacefully or even successfully within our societies, nor prisoners who are not psychopathic. In some parts of our argument we may refer to either the general personality structure of psychopaths, regardless of whether they are imprisoned or not, or to the general normative situation of prisoners, be they psychopathic or not, but the definite outcome of our account depends crucially on the combination of a psychopath's personality structure and the way that imprisonment affects her choices and motivations.

Some of the ethical and practical aspects of the aforementioned scenario have already been discussed in the literature. However, we want here to explore two issues of fundamental normative importance that we believe have not, as of yet, received sufficient attention. More precisely, we will argue that once the psychopathic personality structure is adequately understood, we have reason to doubt that DBS involves an individual medical benefit for a psychopath, and we will question the idea that an imprisoned psychopath could provide voluntary informed consent to such a procedure. A failure to meet these two central ethical requirements casts doubt on whether such a proposal could be ethically justified in either research or therapy.

We start our investigation with a brief account of psychopathy, focusing on its clinical definition and psychosocial characteristics (II). We continue with a short explication of DBS techniques that are currently under discussion with respect to forensic applications in psychopathic delinquents (III). Our main arguments are developed in two subsequent sections. The first is devoted to the issue of individual medical benefit (IV), while the second refers to 
the question of voluntary informed consent $(\mathrm{V})$. We demonstrate that both standards, essential to ethical conduct in both research and therapy, cannot be met when applying DBS techniques to psychopathic inmates. We conclude by summarizing the ethical upshot of our considerations and sketching their impact for a wider range of applications (VI).

\section{Key aspects of psychopathy}

In our brief account of the concept of psychopathy, we follow a "venerable clinical tradition" (Hare and Neumann 2006, p.84) in emphasizing internal personality traits rather than focusing purely on external behavior. This approach is reflected in Robert Hare's Psychopathy Checklist - Revised (PCL-R) (2003), which has come to be regarded as the "dominant assessment instrument" (Patrick 2006, p.xiv) in the area of psychopathy, and noticeably departs from the Diagnostic and Statistical Manual of Mental Disorders, Fifth Edition (DSM-5) (American Psychiatric Association 2013). The DSM, in an attempt to define traits that can be measured reliably, focuses on behavior in its diagnostic category of antisocial personality disorder (ASPD) (Hare 1996; Lykken 2006), which is intended to be the equivalent of psychopathy (American Psychiatric Association 2013; Hare and Neumann 2006). However, this focus on behavior has unintentionally led to a set of diagnostic criteria that, due to the fact that there can be several causes for a given action, is vague and not well suited to psychiatry (Hoeprich 2011; Lykken 2006). Additionally, the criteria are too wide; many more people (especially among the incarcerated population) display the persistently antisocial behavior that characterizes ASPD than plausibly qualify as truly psychopathic (Hare 1996; Hare and Neumann 2006; Hoeprich 2011).

A focus only on behavior obscures the thing that distinguishes the psychopath from much of the incarcerated population: an additional interpersonal-affective component that accompanies antisocial behavior, namely a distinctive "lack of guilt or empathy" (Hoeprich, 2011, p.16). Hare's PCL-R, inspired by the seminal work in the field by Hervey Cleckley (Hare and Neumann 2006; Patrick 2006), provides criteria which include such inferred internal personality traits along with demonstrated behavioral characteristics. A lack of empathy, lack of guilt or lack of conscience is widely regarded as an important hallmark of psychopathy (see for example Cleckley 1955; Hare 1996; Hare and Neumann 2006; Lykken 2006; Maibom 2014; Reid and Gacano 2000). Other affective and interpersonal traits that are often associated with psychopathy are shallow or deficient affect (limits to range and depth of emotion), 
propensity for manipulation and deceit, egocentricity, a sense of entitlement, impulsivity and irresponsibility, and disregard for social conventions (Cleckley 1955; Hare and Neumann 2006; Maibom 2014). In addition to capturing important psychiatric facts about the psychopathic personality which cannot be revealed through a sole focus on behavior, these internal traits are crucial to our ethical focus on what constitutes an individual medical benefit for the psychopath, and whether an incarcerated psychopath can give voluntary informed consent. More precisely, there are two key elements of the psychopathic personality which will be central to our ethical analysis, and thus warrant further brief explication.

First, Cleckley made much of the fact that the psychopath is rational and free of delusion. He noted that psychopaths typically have an unimpaired ability to appraise complex theoretical situations "involving ethical, emotional and other evaluational factors" (1955, p.394). Cleckley's contention here is endorsed by more recent research. Studies by Cima and colleagues as well as Glenn and colleagues found that there were no differences in theoretical moral judgments between psychopaths and non-psychopaths (2010; 2009). Glenn and colleagues noted that there was decreased activity in the amygdala - the area of the brain associated with emotional processing - in psychopaths as they made moral judgments, but that this did not impact on the content of the judgments (2009). Huebner and colleagues similarly argue that rather than emotion founding moral judgments, emotion typically follows moral judgments, and motivates morally relevant action (2009). Consequently, a psychopath's diminished emotional involvement does not impair her ability to make moral judgments but rather her motivation to act accordingly. As Cima and colleagues succinctly put it: "Psychopaths know what is right or wrong, but simply don't care" (2010, p.66).

In this paper, we will accept the claim that psychopaths are not deficient in any theoretical capacity to make moral distinctions, but are rather insusceptible to moral motivation in their practical decisions and behaviors. This lack of moral motivation, though, suffices to pose severe ethical problems concerning psychopaths' assent to experimental or therapeutic interventions into their brains (see Section V).

The second element, that is, for our purposes, important to note, is that there is no subjective suffering involved in psychopathy; psychopaths are perfectly content with and identify with 
their traits. This recognition is sometimes linked to skepticism concerning whether psychopathy is indeed a disorder, or if it is possible to treat it. Cleckley noted that psychopaths do not display any indication that there is something compelling their behavior against their judgment or will. Further, psychopaths do not recognize or feel that something is lacking in their character or motivations, and thus have no desire to overcome their condition (1955). Again, more recent research appears to support these assumptions. Reid and Gacano note that there is nothing painful or egodystonic (i.e. experienced as repugnant, upsetting or dissonant with one's self-conception) in psychopathic symptoms, rendering it unlikely that the psychopath would seek or endure treatment (2000). Some even argue that psychopathy is not a disorder at all, but rather an evolutionarily successful strategy, as "from a certain perspective, what we call deficits are actually advantages" (Maibom 2014, p.34) (e.g. the ability to lie, cheat and steal without experiencing any negative emotional consequences). Further, in general, treating someone involves bringing them back to their normal state, whereas in the case of the psychopath, "treatment aims to change the subject from his or her own norm" (Maibom 2014, p.34). Chartrand, for similar reasons, expresses skepticism over the ability to treat psychopathy, due to the fact that it requires moral commitment and change. That is, he argues, in order to commit being cured of psychopathy, the psychopath must be committed to acquiring a conscience, becoming more empathetic, etc. But it is this precise commitment or motivation that is lacking in the psychopath (2004).

In our analysis, we will, for the sake of argument, accept the idea that psychopathy may be termed a disorder (in the sense of an objective psychological deficit finding expression in deviant social conduct), and we will also accept the suggestion that DBS might offer a cure for it (not necessarily at the deeper level of providing the person affected with missing cognitive or emotional capabilities, but at least at the symptomatic level of reducing or preventing antisocial or criminal behavior). Even if we grant this, however, the absence of subjective suffering from their condition poses severe problems concerning the ethical acceptability of performing brain experiments or therapies on psychopaths (see Section IV).

\section{Deep brain stimulation in psychopathic delinquents}

Despite the skepticism expressed concerning the treatment of psychopaths above, recent neuroscientific developments suggest a new and promising area of inquiry in the treatment of psychopathy. This has led several researchers to propose fertile areas for new research. 
Brain imaging techniques have allowed researchers to identify which areas in the brain are involved when people process moral information, and to highlight differences in the ways that certain parts of the brain function in psychopathic and non-psychopathic individuals (Raine and Yang 2006). De Ridder and colleagues have suggested that because we can identify the areas of the brain that display a difference between psychopaths and normal controls, and then use brain imaging techniques to identify whether differences in activity in a specific brain area in an individual may lead to psychopathic behavior, there may be potential for correcting these differences through deep brain stimulation (DBS) techniques (2009).

DBS is a technique in which electrodes are implanted in the brain and used to electrically stimulate precisely targeted areas (Gkotski and Benaroyo 2012). DBS has been successfully used to treat a range of disorders, including aggressive behavior (Canavero 2014; Hoeprich 2011). This has led several neuroscientists to suggest that brain scans might be used to identify the areas of the brain that are functioning differently in a given psychopathic patient, and that DBS could be used to increase or modulate activity in these areas (see Canavero 2014; De Ridder et al. 2009; Hoeprich 2011). As we can trace psychopathic dysfunction to underactivation or inappropriate activation in specific areas of the brain, modulation of these areas may "cure" psychopaths of their moral dysfunction (Hoeprich 2011). As De Ridder and colleagues point out, because moral dysfunction can be traced to physiological brain dysfunction, moral dysfunction can be "considered a pathological form of brain functioning, just like Parkinson's disease, epilepsy, depression or obsessive-compulsive disorder" (all of which have been treated with DBS) (2009, p.175).

DBS involves, however, inherent risks. Insertion of the devices can cause infection or bleeding in the brain, and stimulation can cause epileptic seizures. If the equipment malfunctions or breaks, additional surgery, which entails further attendant risk, might be required (De Ridder et al. 2009). Depression, apathy, hypomania, euphoria, mirth, hypersexuality and loss of attention or memory have all been documented following DBS procedures, though many of these side effects may be caused by incorrect placement or calibration of the stimulators, and thus may be reversible through reintervention (Burn and Tröster 2004). DBS carries a small risk of mortality (about $0.4 \%$ ) as well as disabling morbidity (about 1\%) (Canavero 2014). 
Research concerning brain imaging and DBS is still in its early stages, and thus proposals that this research should be pursued with psychopathic patients are generally tentative and provisional. However, the calls for further research in this area signify that the possibility of such an approach to "curing" psychopathy is plausible enough to be taken seriously, and thus warrant an exploration of the ethical implications of such a proposal, particularly with a focus on the option of testing and applying DBS in psychopaths that have committed crimes and are detained in prisons.

\section{Individual medical benefit?}

The current state of DBS research and practice suggests that testing or applying this technique in psychopaths with the aim of modifying their behavior would, at least at present, constitute a highly burdensome and risky procedure. Its performance would amount to a major intervention, entailing intense physical strain and possible psychological traumatization, while its inadvertent consequences might be severe, including physiological complications as well as undesired changes in personality. Whether and when this procedure is ethically justified will crucially depend on the questions of whether there is an individual medical benefit to be expected for the subject of the intervention and of whether she gives her voluntary informed consent to that procedure. This holds both for research settings and for prospective "therapies". This section will explore the standard of individual medical benefit and the possibility of its fulfilment in the case of a diagnosed psychopath. In Section V we will turn to the criterion of voluntary informed consent, examining the prospects of securing such consent from psychopathic inmates.

(1) For DBS in psychopathic inmates to be justified, whether it is regarded as research or therapy, it must be accompanied by a realistic chance of a considerable individual medical benefit to the persons involved. With respect to experimentation on detained subjects, where burdens are grave and risks are high the mere promise of enlarged knowledge cannot suffice to justify it unless the research subject herself has a personal chance of profiting from the procedure. Because detained subjects have historically been vulnerable to harm or exploitation in research for the benefit of others, both U.S. and European regulation contains specific restrictions for research on imprisoned subjects, including the requirement that high risk research on prisoners must involve a reasonable probability of direct benefit to the research subject (Council of Europe 2005; U.S. Department of Health and Human Services 2009). In 
a therapeutic scenario, on the other hand, the prospect of individual advantage to the patient is included by definition. More precisely, the aim of benefitting the patient must constitute the very purpose of any biomedical intervention in order to qualify as treatment in the first place (Lasagna 1964; World Medical Association 2006).

However, a closer investigation reveals that an individual medical benefit cannot obtain in the case at issue: a psychopath may have a "disease" or a "disorder", by some commonsensical or medical-psychiatric standard. But DBS cannot be thought to constitute an individual medical benefit for the psychopath, even if it "alleviates" or "cures" her condition. We try to illuminate this point in the following paragraphs.

(2) As stated above, some scholars doubt that psychopathy should be classified as a "disease" or "disorder" in the first place, rather than as a set of traits and behaviors that may be undesirable from a social point of view, but that do not imply any kind of health impairment on the side of the subject. Others are skeptical that this condition might be altered, contending that psychopathy is too deeply embedded in a subject's personality to allow for any successful intervention (see Section II).

In both cases, the criterion of individual medical benefit could not be met: when there is no disease or disorder an intervention cannot be medical, and when there is no success to be expected, there will be no benefit. For the sake of argument, however, we shall assume that both conditions are met, i.e. that psychopaths display some sort of "pathology", in a tenable sense, and that DBS experiments or treatments promise some sort of "remedy", at least in terms of reducing or eradicating psychopathy's most pressing symptoms of deviant behavior.

Even this being granted, however, it does not imply that a psychopath who is subject to DBS in either experiment or therapy could expect an individual medical benefit from the procedure. This seemingly strange constellation is due to the fact that individual medical benefit requires release from, or prevention of, subjective suffering on the side of the person concerned (Cassell 1991). It does not obtain from the mere elimination, or avoidance, of some objective condition that society declares undesirable (even for good reasons). 
A psychopath, though, does not display this kind of subjective suffering from her condition (see Section II). At most, she is subject to the possible distress of impending social sanctions that her behavior may provoke (however justified they may be). So even if we suggest that a psychopath has a "disease" or "disorder", and even if this condition might be relieved or even cured by DBS, this does not suffice to show that there is an individual medical benefit to the subject in question.

(3) This lack of subjective suffering and, consequently, of individual medical benefit implies that DBS on imprisoned psychopaths fails to meet an essential ethical standard for both research and therapy. One may try to evade this problem by referring to other sorts of defects or benefits that an imprisoned psychopath might display or obtain, respectively, but actually none of those replacements will suffice to justify the procedure.

First, it might be envisaged that a psychopath can gain some other individual benefit in return for taking part in DBS research or treatment: particularly, she might be offered reduction or waiver of punishment for her participation. It is far from clear that success rates of the intervention should ever be sufficient to justify such policies. Even proponents of DBS in psychopaths suspect that the danger of psychopathic subjects undermining or sabotaging the operation of their devices does not encourage corresponding practices (De Ridder et al. 2009). More importantly, however, even if release from prison was offered to a psychopathic subject or patient, the benefit would entail freedom from external social sanctions. It would not amount to any cure for any mental or bodily defect. So the individual benefit she might be offered for her participation would still not amount to a medical benefit that could justify the experiments and treatments performed upon her. On the contrary, any offers of this sort would amount to an "undue influence" that prisoners, as a "vulnerable group", are usually thought to have to be protected from (see Section V) (The National Commission 1978; U.S. Department of Health and Human Services 2009).

Second, it might be proposed that release from prison may entail indirect medical benefits to the subject in question: life outside prison may simply be healthier, medical resources may be assessable more easily. But certainly these indirect health effects are not sufficient to justify direct medical interventions. General health advantages outside prison can hardly vindicate any specific medical measures on an inmate. In particular, if these indirect benefits were allowed to 
enter the moral assessment, any medical treatment or experimentation on inmates might eventually be justified by hinting to the healthier lives or the better care that they might expect outside prison. But the prospect of not contracting some disease or of obtaining better medication cannot justify treatment of or experimentation on other, unrelated conditions. To include such indirect benefits in the equation would risk the justification of all sorts of invasive and dangerous techniques on prisoners, with freedom from prison used as leverage to guarantee a favorable balance of benefits. In fact, these indirect benefits would clearly constitute one aspect of the "undue influence" that the prospect of release, with all its social, financial, economic, infrastructural or other advantages, basically entails.

Third, it might be suggested that the psychopath does "suffer" at some deeper level, e.g. by not participating in a kind of "welfare" more broadly construed: we may have reason to regard the psychopath's situation in society as deficient, as lacking substance or fulfilment, and we may feel inclined to state that this condition may be termed a "suffering", or a preclusion of "welfare". However, a medical intervention, particularly when it is as burdensome and risky as DBS, cannot be justified by referring to a kind of "suffering" or "welfare" that is not experienced somatically or psychologically by the individual in question, but rather ascribed to her on social grounds. Objective or intersubjective assessments, however justified they may be, do not imply any subjective suffering that would be required in order to justify medical steps. In particular, such an approach would run the danger of applying to any social outsiders, ostensibly making them suitable objects of medical interventions. For any social outsiders, even when subjectively content with their specific features, may meet with reservation from their environment, and may thus be said to "suffer" or to lack participation in social "welfare". But even if this reservation is well-founded, and even when their condition is to be termed pathological, medical interventions cannot be justified on such grounds. Rather, this approach would amount to a clear example of wrongful "medicalization", i.e. of applying biomedical means without medical indication.

(4) In order to strengthen this point it is instructive to compare the case of the psychopath with a seemingly parallel constellation, i.e. a sexual offender who considers undergoing chemical castration (see Meyer and Cole 1997; Scott and del Busto 2014). This example raises parallel questions concerning the cogency of calling his state a disease, the probability of success and the offender expecting advantages in terms of avoiding punishment. At the same 
time, however, there are notable differences to the case of the psychopath. Most importantly, it is credible that a sexual offender may be adversely affected by his very condition, and not just by the external sanctions he is facing (see Beier et al. 2009). This is not to say that a sexual offender necessarily does suffer from his state. But he may suffer, in contrast to a psychopath, for whom this possibility is excluded if we adhere to the current definitions and assessments of psychopathy. Correspondingly, once it seems justified to assume that a sexual offender (just like the psychopath) has a disorder, it may also be plausible to assume that he (as opposed to the psychopath) is suffering from his disposition. Taken together this may make it plausible that the intervention in question will indeed constitute an individual medical benefit, counterbalancing the burdens and risks of the procedure that he decides to undergo, as opposed to the psychopath, facing her DBS intervention.

The discussion is comparable to debates concerning medical interventions in homosexual desire and behavior that were conducted in the 1950s to early 1970s. For much of this time homosexuality was criminalized in many parts of the world, and was classified as a mental illness by the American Psychiatric Association. Accordingly, some medical research and "treatment" was court-ordered or conducted in exchange for amnesty (APA 2009; Smith, Bartlett and King 2004). We need not dwell on the fact that both categorizations of homosexuality, as a crime and as a disease, were utterly misled. For even if they had been wellfounded, the idea of justifying interventions into the persons concerned by referring to their alleged individual medical benefit would have been flawed: a homosexual is not relieved from any individual suffering when "treated" in his condition, but just from the (unjustified) social sanctions that he has to face. Analogously, a psychopath is not freed from any personal distress when treated for her disposition, but just from the (well-founded) social penalties that she is subjected to.

The resulting combination - a possibly successful cure for an objective disease without individual medical benefit to the person concerned-may appear strange. However, this constellation is bound to obtain whenever a disease is not causing the subject any individual suffering or other immediate obstruction, but only provides the grounds for social reactions-be they adequate, as for the psychopath, or be they inadequate, as for the homosexual — that are promised to be waived when the intervention is performed. In these cases, the presence of the disease does not deliver a medical indication for treating the subject, but only a social 
reason for sanctions against her. And if the disease is cured so that the sanctions may be renounced, no medical purpose for the subject has been achieved, but only a respite from these social sanctions.

In short, the benefit to the individual is not medical (relief from any distress she experiences, consciously or even unconsciously) but social (release from prison that she is sent to, for good or for bad reasons). And the medical success that obtains is no benefit to the individual but to society. This constellation need not preclude any kind of intervention that an imprisoned individual might assent to. But it precludes interventions that are grave enough to require an individual medical benefit on the side of the subject.

\section{Voluntary informed consent?}

What we have said thus far establishes that proposals to conduct DBS research or treatment on an incarcerated psychopath cannot meet essential ethical standards, as well as established US and European legal requirements: the lack of an individual medical benefit precludes the justification of the significant burdens and risks that DBS interventions entail, particularly when discussing their performance on inmates. However, an exclusive focus on whether a psychopath benefits from this procedure obscures a distinct issue which is worth addressing: given what we know of the personality structure of the psychopath, we have good reason to doubt that she would voluntarily consent to DBS. So not only does the psychopath not stand to obtain an individual medical benefit from such a procedure-in fact, she has no internal incentive whatsoever to want such a procedure. Consequently, when the psychopath consents to DBS, we must suspect that she does so due to external pressure and thus under circumstances that we generally think preclude the ability to give voluntary informed consent-which constitutes a separate, essential demand in both research and therapy.

(1) The voluntary informed consent of the subject or patient, respectively, plays a central role in pertinent codes in both research ethics and medical ethics. This requirement has its foundations in the obligation to respect the autonomy or right to self-determination of other persons (The National Commission 1978). At the same time there are serious doubts concerning the voluntariness of consent in prisoners. Inmates constitute a classical "vulnerable group", in danger of being subjected to "undue influence" that might undermine their voluntary decision to agree to any kind of scientific experimentation or non-standard treatment suggested 
to them (The National Commission 1978; U.S. Department of Health and Human Services 2009).

These general worries concerning the voluntariness of prisoners consenting to biomedical interventions are considerably substantiated in the special case of DBS interventions in psychopathic inmates. We will explore this fact by asking a simple, yet essential question: why should we expect an incarcerated psychopath to assent to having a DBS apparatus implanted that is intended to modify her behavior? What, considering the essential elements of psychopathic personality, could be her reasons to agree to such a procedure, particularly given its burdens and risks?

(2) In order to approach this question we turn to a conception of personhood that was sketched by Harry Frankfurt (1971) and is well-suited for analyzing attitudes and decisions concerning one's own inclinations and preferences. This account is particularly useful in pinpointing problems with internally arising, yet repudiated actions, which characterize many types of psychiatric illness (Faden and Beauchamp 1984), and thus may prove informative for understanding an imprisoned psychopath's motivation for agreeing to a neuroscientific intervention which is meant to change her deviant behavior. Following this Frankfurtian conception, persons are distinguished by a two-level structure of "first-order desires", directed at possible actions, and "second-order desires", targeted at just those first-order desires. More precisely, a person's "will" is an action-effective first-order desire, while a person's "volition" consists of a second-order desire that "wants" a specific first-order desire to be, or to be not, action-effective, i.e. to be one's “will”. At times, persons may experience a discrepancy between their "will" and their "volitions". They then may try to bring the former under the control of the latter.

Returning to the example of a sexual offender opting for chemical castration (see Section IV) we find how illuminating this Frankfurtian model can be in reconstructing delinquents' decisions to cope with their psychological dispositions. As stated above, we can conceive of a sexual offender as having a "disease" (and even as subjectively suffering from it), and we may reconstruct this "disease" as an inability to control his sexual desires that threaten to make him behave in ways that he actually repudiates (being deeply repelled by his own violent inclinations). Chemical castration then, for the sexual offender, could be envisaged as a 
means of regulating or eliminating certain "first-order desires" that he disapproves of from the perspective of his reflective "second-order desires". More precisely, chemical castration could provide him with the opportunity to calm down or even switch off his criminal predisposition, so that he, or rather one of his second-order "volitions", regains higher-order control over his action-effective "will", and consequently his behavior.

In particular, conceiving of the situation in this way, we might suggest that the sexual offender, in assenting to chemical castration, makes a voluntary (second-order) decision to suppress or eradicate certain (first-order) inclinations. Though he acts upon his impulses, he may welcome such treatment as an opportunity to allow him to do what he really wants to do, to be the kind of person he really wants to be (see also Dworkin 1988). Though his immoral impulses arise internally, the sexual offender may not regard them as part of his real personality. In contrast, while his wish to overcome them is also internal, it is much more central to his normative self-conception.

Frankfurt's model, therefore, provides us with a useful tool for approaching this type of case. It allows us to see how some desires, though they come from within, can be regarded as alien or obstructive, and how offering someone techniques to overcome these desires may provide him with the means to act in a way that he really wants.

(3) The idea of a psychopath consenting to DBS to "treat" her "disorder" seems to be based upon similar reasoning: DBS can modulate certain areas of the brain that are associated with violent or impulsive behavior. This suggests that DBS can provide a similar means of controlling "first-order desires" that a psychopath might repudiate from the perspective of her "second-order desires". More precisely, in having a DBS device implanted, a psychopath might want to bring her bad (first-order) "will" into line with her good (second-order) "volitions"-following her moral considerations to control her immoral inclinations. However, from what we have presented so far, an immediate problem with this approach in the case of the psychopath should be apparent: unlike a sexual predator, the psychopath does not have a functioning moral framework that is merely threatened to be overrun by the presence of offensive appetites which she might try to tame or suppress, accordingly. What characterizes the psychopath is rather a lack of moral motivation (see Section II). A psychopath may be acquainted with moral rules, but they do not constitute effective reasons for her; she may have 
the relevant moral knowledge to differentiate between right and wrong, but she does not have the inherent moral motivation to act accordingly_-regardless of whether we want to locate it on the level of her (first-order) "will" or of her (second-order) "volitions".

This is not just a problem concerning the obvious deficit of moral intention in the psychopath's consent to a DBS intervention. It is a problem concerning the very voluntariness of her decision. All evidence suggests that the psychopath's behavior is not the manifestation of overwhelming drives which she cannot identify with and wishes to be freed from. On the contrary, a typical psychopath approves of her own attitude and merely shuns the social consequences that she might be exposed to (see Section II). DBS in a psychopath, then, cannot be conceived of as a means of allowing her to regulate or eliminate some "first-order desires" that she disapproves of from the perspective of her "second-order desires". Unlike the sexual predator, she cannot regard the intervention as an option to act in a way that she really wants to act. However, if a decision to undergo DBS or any other behavior-regulating procedure cannot arise from the psychopath's internal motivations, we have reason to suspect that wherever the psychopath consents to such a procedure, particularly when it is as burdensome and risky as DBS, she is doing so due to external pressure. This casts the voluntariness of her consent into serious doubt.

Again, a parallel with homosexuality will be illustrative here: in this day and age, where a homosexual person consents to some sort of conversion therapy to remove his homosexual desires, we would be likely to say that this is problematic. In particular, we would suspect that he is acting due to external pressure (e.g. from an extremely religious community) (see APA 2009). The character structure of a psychopath brings us to a similar conclusion concerning her decision to seek DBS: the psychopath cannot be construed as an individual who struggles against her desires or behaviors. So again, any willingness to conform to socially acceptable behavior must come from external, rather than internal sources, thus undermining the voluntariness of her decision.

In fact, the case of a psychopath is even more unambiguous, as a homosexual person can certainly internalize societal standards (although we may deplore exactly this internalization as a distorting result of coercive pressure). The psychopath, by contrast, in virtue of being a psychopath, cannot internalize societal expectations (which we may actually regret). This 
makes it ever more obvious that where a psychopath consents to behavior-changing interventions, she is doing so solely as a result of external pressure. And as long as we require voluntary, uncoerced consent as a precondition for any intervention into her brain, a psychopath's (regrettable) lack of internal motivation for having her behavior altered is at least as much of an ethical obstacle as a homosexual's (justified) lack of authentic motivation to undergo "treatment" for his "disease".

(4) The fact that psychopaths do not feel estranged from their deviant disposition made us conclude in Section IV that psychopaths cannot be said to subjectively suffer from their condition and thus cannot obtain an individual medical benefit from being "cured". Essentially this same lack of estrangement serves us now to state that psychopaths have no internal motivation for having their behavior changed and thus cannot give voluntary informed consent to such a "cure". Voluntary informed consent, though, is an essential precondition for any experimental or therapeutic intervention, particularly when it is burdensome and risky, even more so when we approach an inmate, and no matter how much we abhor a psychopath's behavior. A psychopath, however, cannot have any internal motivation to consent, and the special situation of being incarcerated makes external pressure the only plausible source of her cooperation, particularly given the burdens and risks of the intervention, thus undermining her voluntariness.

It is tempting to insist that a psychopath, though not making moral decisions, may still make rational decisions. So it might be asked why a psychopath should be denied the opportunity to decide for herself whether she wants to undergo the given burdens and risks in exchange for release from prison. However, this framing of the problem simply masks the coercive character of the situation: it might as well be asked why a rational man should not be given the opportunity to decide whether he wants to lose his purse or his life. And the answer is obvious: as long as he has no internal motivation for giving away his purse, it is clearly the coercion in the prospect of losing his life that will make him hand his money over. Analogously, as long as a psychopath has no internal motivation for undergoing DBS, it is clearly the coercion in the prospect of imprisonment that makes her agree to the intervention. It is this coercive element inherent in her decision, rather than any supposed lack of rationality on the psychopath's part, which makes the prospect of this procedure unacceptable. This verdict cannot be qualified by hinting at the fact that psychiatry traditionally regards some individuals 
as eligible for treatment, although they are unable to consent. For such decisions can only be justified by referring to some individual medical benefit of the individuals in question. Coercive treatment without subjective suffering is deeply inappropriate, coercive experiments not involving the relief of subjective suffering are even less defensible. As psychopaths do not experience such suffering (see Section IV), coercive interventions on them cannot be justified.

Merkel and colleagues disagree with this contention, arguing that there is no coercion involved in suggesting brain interventions on prisoners in exchange for release as long as the impending detainment is based on rightful legislation. Allegedly, pressure exerted by legitimate laws is comparable to "the compelling force of natural circumstances", which never compromises autonomy. It is not like pressure exerted by single persons or totalitarian regimes, which may indeed impose someone else's will on a decision-maker (2007, p.381f.). This line of argument, however, is problematic for two reasons. Firstly, neither their nonindividual character nor their assumed legitimacy changes the fact that laws differ, in significant aspects, from 'natural circumstances'. Laws, whether ethically legitimate or not, constitute anthropogenic pressure which is designed to restrict the activities of individuals, and so, by definition, they amount to coercion. It is true that this coercion does not come into effect as long as an individual's internal motivation is coherent with the legislation in question. But when an individual has no internal motivation for submitting to a given regulation (as is the case with a psychopath in face of legislation which is meant to alter her behavior) it clearly restricts her autonomy, as this is the very purpose of the law, and when the individual agrees to some intervention only to escape corresponding sanctions (like a detained psychopath agreeing to DBS) her consent cannot be regarded as voluntary, no matter how justified the regulation may be. Secondly, even if we were to accept, for the sake of argument, that legitimate laws are indeed akin to natural circumstances, that do not, on their own, constitute coercion, it does not follow that the offer to the imprisoned psychopath to participate in this procedure should not be understood as coercive. That is, even if imprisonment itself was regarded as non-coercive, the circumstances of imprisonment would still make the offer to the detained psychopath coercive.

This becomes more tangible when we turn to the influential account of autonomy and informed consent provided by Faden and Beauchamp. In their elucidation of the concept of 
controlling influences, they specifically approach the problem of persons who find themselves in pressing natural or social circumstances and who are offered certain advantages in exchange for undergoing biomedical interventions. As a rule of thumb they suggest that such proposals do not compromise the ability to give a voluntary informed consent as long as the offer is "reasonably foreseeable as welcomed or easily resistible" (1984, p.361). For example, if some proposed research, rather than entailing a painful and hazardous surgical procedure, involved a series of interesting and non-intrusive interviews, we might imagine that subjects, while still being motivated by the additional advantages they are offered, would be pleased to take part in the experiment and so, due to the fact that they wholeheartedly and unreservedly welcome the opportunity to participate, are still in control of their decision, rather than giving in to the wishes of the researcher. On the other hand, if the offer would not amount to a significant improvement of their situation, it would be easily resistible so that the decision to participate, again, may be regarded as autonomous. The offer to conduct DBS on an imprisoned psychopath in exchange for release fails this test on both counts. Due to the fact that the procedure is burdensome and risky, that it entails no individual medical benefit for the psychopath, and that the psychopath has no reason to want such treatment for lack of moral motivation or any other desire for psychological change, significant doubt is cast on whether this offer is "welcome" (the fact that we would not expect a non-imprisoned psychopath to seek or consent to such a procedure lends credence to this). On the other hand, because the psychopathic offender is confronted with a choice between the procedure and imprisonment, it is clear that she is not facing an easily "resistible" offer (given the burdens and risks, the lack of subjective suffering and the lack of internal motivation, only the irresistibility of the offer makes it plausible that the psychopath might be interested in it at all). Consequently, where a psychopath does consent to this procedure, we have reason to suspect that it is due to feeling compelled to do so, and thus a situation where the researcher is imposing his will on the subject, rather than an instance of an autonomous decision against a fair offer.

\section{Conclusion}

We have discussed the idea of applying DBS techniques to psychopathic inmates in order to change their delinquent behavior, either in experimental or in therapeutic settings. We have argued that these suggestions fail to comply with two fundamental standards of research ethics and medical ethics: first, due to the lack of subjective suffering from her objective 
condition a psychopath has no individual medical benefit from the procedure. Second, the fact that the psychopath lacks the internal motivation to change her traits and behaviors gives us reason to doubt that the psychopath gives voluntary informed consent. Thus, two of the most fundamental ethical requirements of research and treatment cannot be met by this proposal.

This problem cannot be removed by appealing to the possibility that an imprisoned psychopath, after being "cured" from her "disease" via DBS, might eventually deplore her former state and approve of the intervention. For in spite of this retrospective endorsement, the two conditions of individual medical benefit and voluntary informed consent could not be met at the time of the decision. There is no way to get to this result without violating these two principles. Given that they are generally seen as essential to ethical conduct, we contend that the end here cannot be said to justify their violation.

One might further object that our focus on fundamental standards for medical research and medical therapy is misguided, in that DBS for psychopathic inmates need not be regarded as a medical procedure at all, and could rather be classified as, for example, 'moral enhancement'. We would warn against this approach for two reasons. Firstly, it appears highly dubious to pursue such a re-classification, given the personal and institutional settings in which DBS in psychopathic inmates is foreseeably to be performed. It would be an all-too-obvious maneuver if researchers and doctors who are currently envisaging and preparing corresponding interventions simply changed their self-declaration in order to escape those standards that they are tied to by their education, their affiliation, the purposes of their projects and the character of their practices. Secondly, even if we imagined that, at some point, these interventions might indeed take place outside the medical sector, this change of category would not change the ethical setup of the situation and the normative problems that it entails. The procedure would still be a highly burdensome and risky intervention into the psychopath's bodily and mental integrity, while the psychopath does not experience any subjective suffering or distress. The psychopath would still have no internal motivation to undergo the procedure and would agree to it only due to the pressure of imprisonment, or the prospect of release, thus giving in to coercion. It is hard to see how these factors would not prove problematic for an intervention which is so burdensome and risky and which is meant to be performed on an inmate-no matter how the procedure is labeled. 
Due to our focus on ethical standards that are widely accepted as essential in all experimental and therapeutic situations, our treatment of the specific question of DBS in imprisoned psychopaths may have wider ethical implications. We cannot provide an exhaustive account of what these implications may be here, but we make the following suggestions. Firstly, similarly invasive neuroscientific techniques, including psychochemical or psychopharmacological interventions, should be met with the same reservations when their application on psychopathic detainees is considered: the lack of individual medical benefit as well as of voluntary informed consent will pose a problem, at least whenever burdens and risks are significant. Secondly, the peculiar constellation of psychopathic prisoners is essential in arguing that the standards of medical benefit and informed consent cannot be met: the argument does not straightforwardly translate to non-incarcerated psychopaths or to non-psychopathic offenders, such as sexual predators (who, consequently, served as counter-examples in the above discussion). This does not imply, of course, that there may not be good reasons to refrain from interventions in these groups, too (because of unbearable medical risks, unacceptable personality changes, impending undue influence, or the belonging to a vulnerable group).

Yet it does imply that the idea of imprisoned psychopaths constituting a particularly suitable group for DBS research or therapy is flawed. Their condition may make these interventions highly attractive, supposedly acknowledging their "disease" status and possibly opening an attractive alternative to usual punishment. However, as we have shown, it is exactly the nature of the psychopathic inmate's "disease" that makes DBS in this case so problematic. Consequently, common measures of detention may, upon consideration, turn out to be more adequate in interacting with psychopathic delinquents, and more consistent with the ethical standards we extend to all subjects and patients. Setting limits to their dangerous behavior and communicating disapproval with their immoral attitude may be more appropriate and more humane than subjecting them to experiments or treatments that they do not benefit from and cannot consent to. Our comprehensible wish to alter them cannot override their lacking wish to change - as long as we do not want to give in to exactly that kind of expedient, non-moral thinking that we deplore in them.

\section{References}

American Psychiatric Association. 2013. Diagnostic and statistical manual of mental disorders, $5^{\text {th }}$ ed. Washington, DC: American Psychiatric Association. 
APA Task Force on Appropriate Therapeutic Responses to Sexual Orientation (APA). 2009. Report of the task force on appropriate therapeutic responses to sexual orientation. Washington, DC: American Psychological Association. Available at: http://www.apa.org/pi/lgbt/resources/therapeutic-response.pdf

Beier, K., C. Ahlers, D. Goeker, J. Neutze, I. Mundt, E. Hupp and G. Schaefer. 2009. Can pedophiles be reached for primary prevention of child sexual abuse? First results of the Berlin Prevention Project Dunkelfeld (PPD). Journal of Forensic Psychiatry and Psychology 20(6): 851-67. Available at: http://dx.doi.org/10.1080/14789940903174188

Burn, D., and A. Tröster. 2004. Neuropsychiatric complications of medical and surgical therapies for Parkinson's disease. Journal of Geriatric Psychology and Neurology 17(3): 172-80. Available at: http://dx.doi.org/10.1177/0891988704267466

Canavero, S. 2014. Criminal minds: Neuromodulation of the psychopathic brain. Frontiers of Human Neuroscience 8: 124. Available at: http://dx.doi.org/10.3389/fnhum.2014.00124

Cassell, E. 1991. The nature of suffering and the goals of medicine. New York: Oxford University Press.

Chartrand, L. 2004. Character: Moral treatment and the personality disorders. In J. Radden (ed.) The philosophy of psychiatry: A companion. New York: Oxford University Press, 65-77.

Cima, M., F. Tonnaer, and M. Hauser. 2010. Psychopaths know right from wrong but don't care. Social Cognitive and Affective Neuroscience 5(1): 59-67. Available at: http://dx.doi.org/10.1093/scan/nsp051

Cleckley, H. 1955. The mask of sanity: An attempt to clarify some issues about the so-called psychopathic personality, $3^{\text {rd }}$ ed. Saint Louis: Mosby. 
Council of Europe. 2005. Additional protocol to the convention of human rights and biomedicine, concerning biomedical research. Strasbourg: Council of Europe. Available at: http://conventions.coe.int/Treaty/en/Treaties/Html/195.htm

De Ridder, D., B. Langguth, M. Plazier, and T. Menovsky. 2009. Moral dysfunction: Theoretical model and potential neurosurgical treatments. In J. Verplaetse, S. Vanneste, J. Braeckman, and J. Schrijver (eds.) The moral brain: Essays on the evolutionary and neuroscientific aspects of morality. Dordrecht: Springer Netherlands, 155-184.

Dworkin, G. 1988. The theory and practice of autonomy. Cambridge: Cambridge University Press.

Faden, R., and T. Beauchamp. 1986. A history and theory of informed consent. New York: Oxford University Press.

Frankfurt, H.G. 1971. Freedom of the will and the concept of a person. The Journal of Philosophy 68(1): 5-20.

Gkotski, G., and L. Benaroyo. 2012. Neuroscience and the treatment of mentally ill criminal offenders: Some ethical issues. Journal of Ethics in Mental Health 6(Suppl.): 1-6. Available at: http://www.jemh.ca/issues/v6/documents/JEMH Vol6 SupplementArticle-Neuroscienceandthe'TreatmentofMentallyIllCriminalOffenders.pdf

Glenn, A., A. Raine, R. Schrug, L. Young and M. Hauser. 2009. Increased DLPFC activity during moral decision-making in psychopathy. Molecular Psychiatry 14(10): 909-911. Available at: http://dx.doi.org/doi:10.1038/mp.2009.76

Hare, R. 1996. Psychopathy and antisocial personality disorder: A case of diagnostic confusion. Psychiatric Times 13(2): 39-40. Available at: http://www.psychiatrictimes.com/antisocial-personality-disorder/psychopathy-and-antisocial-personality-disorder-case-diagnosticconfusion

Hare, R. 2003. The psychopathy checklist - revised, $2^{\text {nd }}$ ed. Toronto: Multi-Health Systems. 
Hare, R., and C. Neumann. 2006. The PCL-R assessment of psychopathy. In C. Patrick (ed.), Handbook of psychopathy. New York: The Guilford Press, 58-88.

Hoeprich, M. 2011. An analysis of the proposal of deep brain stimulation for the rehabilitation of criminal psychopaths. Presentation for the Michigan Association of Neurological Surgeons. 11 June 2011. Available at: http://www.destinationmi.com/documents/2011MANSpresentation MarkHoeprich.pdf

Huebner, B., S. Dwyer, and M. Hauser. 2009. The role of emotion in moral psychology. Trends in Cognitive Science 13(1): 1-6.

Lasagna, L. 1964. Hippocratic Oath - modern version. Association of American Physicians and Surgeons, Inc. Available at: http://www.aapsonline.org/ethics/oaths.htm

Lykken, D. 2006. Psychopathic personality: The scope of the problem. In C. Patrick (ed.) Handbook of psychopatby. New York: The Guilford Press, 3-13.

Maibom, H.L. 2014. To treat a psychopath. Theoretical Medicine and Bioethics 35(1): 31-42.

Merkel, R., G. Boer, J. Fegert, T. Galert, D. Hartmann, B. Nuttin, and S. Rosahl. 2007. Intervening in the brain: Changing psyche and society. Berlin: Springer.

Meyer, W. and C. Cole. 1997. Physical and chemical castration of sex offenders: A review. Journal of Sex Offender Rehabilitation 25(3-4): 1-18.

Patrick, C. (ed.) 2006. Handbook of psychopathy. New York: The Guilford Press.

Raine, A., and Y. Yang. 2006. Neural foundations to moral reasoning and antisocial behavior. Social Cognitive and Affective Neuroscience 1(3): 203-13. Available at: http://dx.doi.org/10.1093/scan/ns1033 
Reid, W., and C. Gacano. 2000. Treatment of antisocial personality, psychopathy, and other characterologic antisocial syndromes. Behavioral Sciences and the Law 18(5): 647-662.

Scott, C., and E. del Busto. 2014. Chemical and surgical castration. In R. Wright (ed.) Sex offender laws: New policies, failed directions. New York: Springer, 190-218.

Smith, G., A. Bartlett, and M. King. 2004. Treatments of homosexuality in Britain since the 1950s-an oral history: the experience of patients. British Medical Journal 328(7437): 427429

The National Commission for the Protection of Human Subjects of Biomedical and Behavioral Research (The National Commission). 1978. The Belmont Report: Ethical principles and guidelines for the protection of human subjects of research. Washington: U.S. Government Printing Office.

U.S. Department of Health and Human Services. 2009. Title 45, Code of Federal Regulations, Part 46, Regulations for the Protection of Human Research Subjects (45 CFR 46). Available at: http://www.hhs.gov/ohrp/policy/ohrpregulations.pdf

World Medical Association. 2006. WMA International Code of Medical Ethics. World Medical Association. Available at: http://www.wma.net/en/30publications/10policies/c8/ 